\title{
Characterization of ancient harappan faience bangles
}

Gilberto Artioli ${ }^{1}$, Ivana Angelini², Massimo Vidale ${ }^{2}$

${ }^{1}$ Geosciences, UNIPD, Padova, Italy, ${ }^{2}$ Dipartimento di Beni Culturali DBC, UNIPD, Padova, Italy E-mail: gilberto.artioli@unipd.it

Several types of faience were produced by the Indus Valley civilizations during the Early (3300-2600 BC), Middle (2600-1900 BC), and Late Harappan (1900-1300 BC) periods [1], including faience, glassy faience, and glazed terra-cottas. A special kind of high-strength faience was manufactured by multiple-step grinding and fritting procedures [2] to produce wearresistant bangles. Several fragments of such high-strength faience from Harappa and Moenjodaro were analysed by XRPD, SEM-EDS, and Raman spectroscopy in order to check for similar production techniques and starting raw materials between the two archaeological sites, and compare them to previous characterization [2]. The phase purity, the observed high amount of cristobalite, and the textural homogeneity of the samples agree with the proposed multiple fritting preparation procedure.

[1] Keynoyer, J.M. (1994) Ornament, 17, 36-39.

[2] McCarthy, B. \& Vandiver, P. (1991) MRS Symposium Proceedings, 185, 495-510.

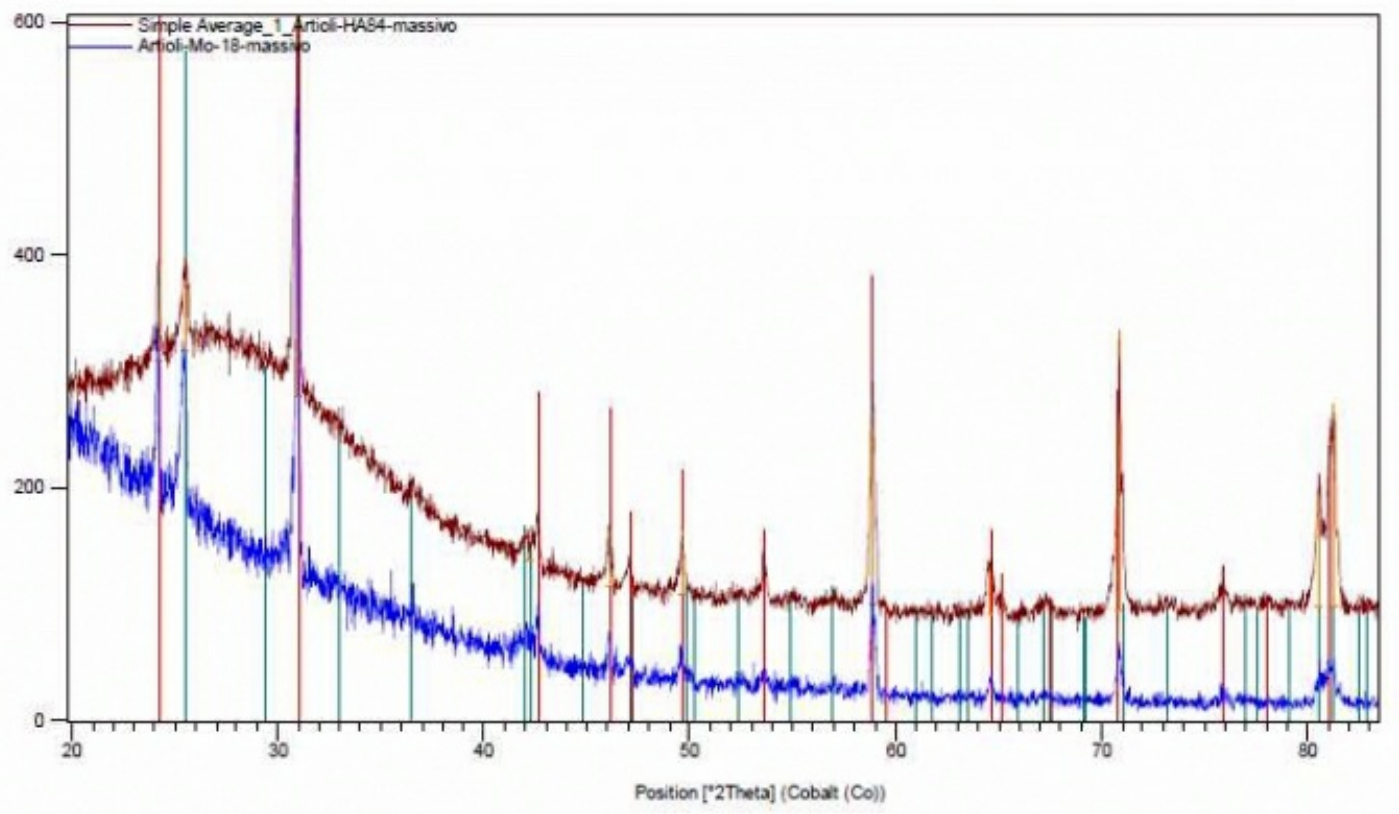

Keywords: archaeometry, ancient faience, Indus Valley civilizations 